Nevşehir Bilim ve Teknoloji Dergisi Cilt 6(1) 39-51 2017

DOI: 10.17100/nevbiltek.271047

URL: http://dx.doi.org/10.17100/nevbiltek.271047

\title{
Hareketli Yatak Biyofilm Reaktörler
}

\author{
Osman Önder NAMAL ${ }^{1, *}$ \\ ${ }^{1}$ Nevşehir Hacı Bektaş Veli Üniversitesi, Mühendislik - Mimarlık Fakültesi, Çevre Mühendisliği Bölümü, \\ Nevşehir \\ Öz
}

Nüfus artışı ve sanayileşme su tüketimindeki artışları da beraberinde getirmektedir. Su tüketiminin artması temiz su kaynaklarında azalmaya yol açmaktadır. Bu durumda atıksu arıtımı giderek daha fazla önem kazanmaktadır. Atıksu arıtımında biyolojik arıtma prosesleri büyük bir öneme sahiptir. Atıksuların biyolojik arıtımında yaygın kullanılan prosesler askıda büyüyen sistemler (aktif çamur prosesleri gibi) ve biyofilm sistemler (damlatmalı filtreler gibi) olarak ikiye ayrılır. Her iki sisteminde sunduğu belirli avantaj ve dezavantajlar bulunmaktadır. Arıtma verimini ve etkinliğini artırmak için günümüzde her iki sistemin de avantajlarını bir araya getiren hibrid sistemler üzerine yapılan çalışmalar yoğunluk kazanmıştır. Hareketli yatak biyofilm reaktör teknolojisi de bu hibrid sistemlerden bir tanesidir. Bu çalışmada, hareketli yatak biyofilm reaktör teknolojisi üzerine literatürde bulunan mevcut çalışmalar incelenerek bir arada sunulmuştur.

Anahtar Kelimeler: Atıksu, arıtma, hareketli yatak biyofilm reaktörler

\section{The Moving Bed Biofilm Reactors}

\section{Abstract}

The population growth and industrialization brings with increasing in the water consumption. The increasing of water consumption causes to reduction of clean water sources. Biological treatment processes has an great imprtance in the wastewater treatment. Commonly used processes in biological treatment of wastewaters divides into two as suspended growth systems (e.g. activated sludge processes) and biofilm systems (e.g. trickling filters). There is specific advantages and disadvantages offered by the both systems. Nowadays, to enhance the treatment productivity and efficiency, the studies on hybrid systems which combines the advantages of the both systems is intensifies. Also, the moving bed biofilm reactors, one of the these hybrid systems. In this study, available studies in the literature on moving bed biofilm reactor technology was presented together.

Keywords: Wastewater, treatment, moving bed biofilm reactors

*e-mail: osmannamal@nevsehir.edu.tr 
1. Giriş

Temiz su kaynaklarının azalması ve artan kentleşme su kalitesini korumak için daha gelişmiş bir teknoloji gerektirmektedir [1]. Arıtılmamış ya da yetersiz arıtılmış atıksular çevreye deşarj edildiğinde ötrofikasyon, oksijen tükenmesi ve toksisite gibi bazı problemlere neden olmaktadır [2]. Su kalitesini etkileyen en önemli faktörler; organik madde içeriği ile su ortamındaki azot ve fosfor gibi nutrientler olarak sıralanabilir. İkincil arıtma, evsel atıksu arıtma tesislerinde bu kirleticilerin giderildiği temel bir prosestir [3]. Atıksu arıtma tesislerinde ikincil arıtma genellikle ya askıda biyokütle ya da biyofilm sistemler olarak sınıflandırılan biyolojik prosesler tarafından sağlanır [4]. Aktif çamur prosesleri gibi askıda biyokütle teknolojisine dayalı biyolojik arıtma prosesleri evsel atıksulardan organik madde ve nutrient gideriminde etkilidir [5]. Ancak bu prosesler yüksek hidrolik ve organik yüklere maruz kaldığında çamurun çöktürülmesinde bazı sorunlar ortaya çıkmaktadır [6, 8]. Ayrıca; aktif çamur proseslerinde büyük reaktörlere, çökeltim tanklarına ve çamur geri devrine ihtiyaç duyulmaktadır [7].

Biyofilm proseslerde, aktif çamur prosesindeki bazı problemler olmadan organik karbon ve nutrient giderimi sağlamak mümkündür $[3,8]$. Tek bir biyofilm reaktörde hem nitrifikasyon hem de denitrifikasyon ayrı olarak başarı ile gerçekleştirilebilmektedir [9]. Ayrıca biyofilm prosesler amonyak gideriminin en ekonomik ve ideal yolu olarak dikkate alınır [10]. Mevcut durumda, suyun biyolojik arıtımında damlatmalı filtreler, döner biyolojik kontaktörler, sabit yataklı batık biyofiltreler, tanecik yataklı biyofiltreler, akışkan yataklı reaktörler gibi birçok biyofilm sistem kullanılmaktadır ve bu sistemlerin tamamı avantaj ve dezavantajlara sahiptir [11]. Damlatmalı filtreler hacimsel olarak etkili değildir. Döner biyolojik kontaktörlerde sıklıkla mekanik sorunlar yaşanmaktadır. Sabit yataklı batık biyofiltrelerde yükün tüm taşıyıcı yüzeyine dağılımını sağlamak oldukça zordur. Tanecik yataklı biyofiltreler ise geri yıkama gereksinimi nedeniyle sürekli olarak işletilemezler ve birçok akışkan yataklı reaktör hidrolik olarak kararsızlık gösterir [12]. Biyofilm proseslerde karşılaşılan diğer bir sorun biyofilm katmanları boyunca substratların ve oksijenin difüzyonunun kısıtlanmasıdır, bu durum biyofilm kalınlığı arttıkça daha kritik bir hale gelmektedir [13]. Ayrıca, biyofilm proseslerin kanallaşma ve tıkanma gibi sistem performansını düşüren dezavantajları bulunabilmektedir [14]. Bu nedenle aktif çamur ve biyofilm sistemlerin avantajlarını birleştiren hibrid sistemler üzerindeki çalışmalar yoğunluk kazanmıştır ve hareketli yatak biyofilm reaktörler hibrid sistemler içerisinde en fazla kullanılanlardan biridir [15].

\section{Hareketli Yatak Biyofilm Reaktörlerin Tarihçesi ve Çalışma Prensibi}

Hareketli yatak biyofilm reaktörler, 1990'ların başında Norveç’te konvansiyonel aktif çamur reaktörlerine kompakt bir arıtma alternatifi olarak geliştirilmiştir [16, 17] ve ilk önceleri soğuk iklim koşulları için tasarlanmıştır [18]. Bu reaktörlerin geliştirilmesindeki temel fikir; aktif çamur ve biyofilm proseslerin en iyi özelliklerinin tek reaktörde bir araya getirilmesidir [19]. Hareketli yatak biyofilm reaktörler sürekli akışlı olarak işletilirler ve taşıyıcı denilen elemanlardan oluşur. Söz konusu taşıyıcı elemanların temel görevi biyofilmin gelişimi için alan sağlamaktır. Bu reaktörler anoksik ve aerobik olarak işletilebilmektedir [21]. Taşıyıcı elemanlar sudan biraz daha az bir yoğunluğa sahiptir ve reaktör içerisinde serbestçe hareket ederler. Bu hareket aerobik reaktörlerde havalandırma, anaerobik ya da anoksik reaktörlerde ise mekanik karıştırma ile sağlanır (Şekil 1) [22]. Böylece suyun sirkülasyonu ile birlikte reaktör içerisinde hareket eden taşıyıcılar mekanik ya da hidrodinamik olarak karıştırılmış olur. Suyun sirkülasyonu ile oluşan yüksek kayma gerilmesi ve taşıyıcıların çarpışması, biyofilm gelişiminin 
kontrolüne yardımcı olarak reaktör sistemini stabilize eder [23]. Ayrıca taşıyıcıları reaktör içerisinde tutmak için reaktör çıkışına bir ızgara yerleştirilir [24].

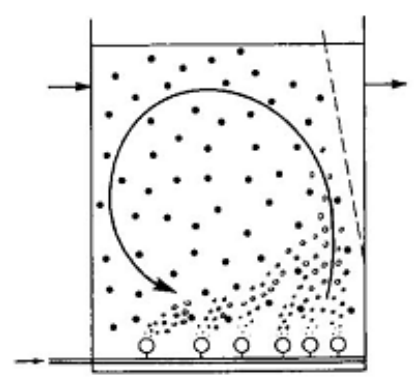

(a)

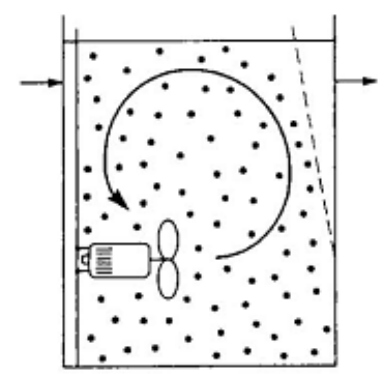

(b)

Şekil 1. (a) Aerobik ve (b) Anoksik veya anaerobik hareketli yatak biyofilm reaktör [52]

Çoğu biyofilm reaktörün aksine hareketli yatak biyofilm reaktörlerde biyokütle gelişimi için tüm tank hacmi kullanılır ve aktif çamur reaktörlerinin aksine herhangi bir çamur geri devrine ihtiyaç duyulmaz [12]. Hem reaktör hacmi hem de alan gereksinimi nispeten düşüktür [23, 25]. Taşıyıcı elemanlar yapışık mikrobiyal biyofilm gelişimi için büyük bir yüzey alanı sağlayacak şekilde özel olarak tasarlanmıştır [28]. Yüksek yüzey alanına sahip olan taşıyıcılar mikroorganizmaların adsorpsiyonu ve gelişimi için yüksek bir miktarda alan sağlar [20]. Bu sayede son çöktürücüye gelen MLSS konsantrasyonunda önemli herhangi bir artış olmaksızın reaktörde yüksek bir biyokütle konsantrasyonu elde etmek mümkündür [4]. Bu durum verilen bir reaktör hacmi için biyolojik arıtma kapasitesini artırır [29]. Böylece hem reaktörde yüksek bir biyokütle sağlanır [30] hem de çamur geri devrine ihtiyaç duyulmaz [31].

Wen ve çalışma arkaddaşları hareketli yatak biyofilm reaktörlerde havalandırma hızının arıtma verimini doğrudan etkilediğini bildirmişlerdir [32]. Aerobik bir reaktöre oksijen sağlamak için genellikle iri kabarcıklı ve jet havalandırma sistemleri kullanılır [33]. Bu sistemlerde ince kabarcıklı havalandırma kullanıldığında taşıyıcıların hava kabarcıklarının toplanmasına neden olduğu ve böylece oksijen transfer veriminin düştüğü bildirilmiştir [34]. İri kabarcıklı havalandırma ile kıyaslandığında kuvvetli bir karıştırma ve yüksek oksijen transfer verimi nedeniyle jet havalandırma önerilmektedir [33].

Hareketli yatak biyofilm reaktörlerde doluluk oranı en önemli parametrelerden birisidir [35]. Doluluk oranı taşıyıcıların kapladığı hacim ile toplam tank hacmi arasındaki oran olarak tanımlanır ve iyi bir karışım için maksimum değeri 0.7'dir [36]. Taşıyıcıların serbestçe hareket etmesini sağlamak için doluluk oranının \%70'in altında olması önerilmektedir [37]. Qui ve çalışma arkadaşları \%20 ile \%60 arasında değişen farklı doluluk oranlarında kok atıksuyu ile yaptıkları çalışmada \%50 doluluk oranına sahip reaktörde maksimum performans gözlemişlerdir [6]. Ayrıca, \%35 ve \%66 olmak üzere iki farklı dolum oranı ile yapılan pilot ölçekli bir çalışmada organik madde giderimi için \%35 dolu olan reaktörün daha iyi bir performans gösterdiği ve her iki reaktörün de \%99'a kadar nitrifikasyon performansı sergilediği bildirilmiştir [27]. 
(a)

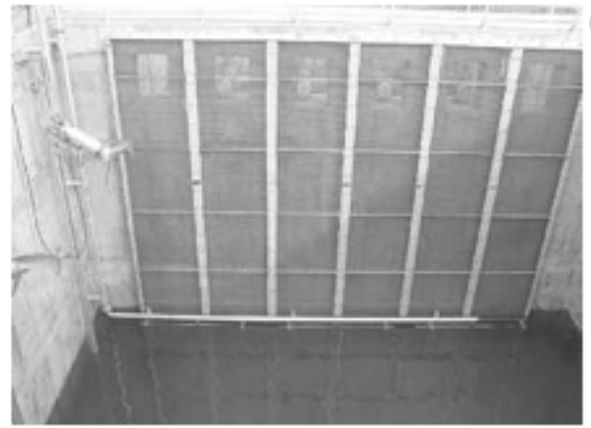

(b)

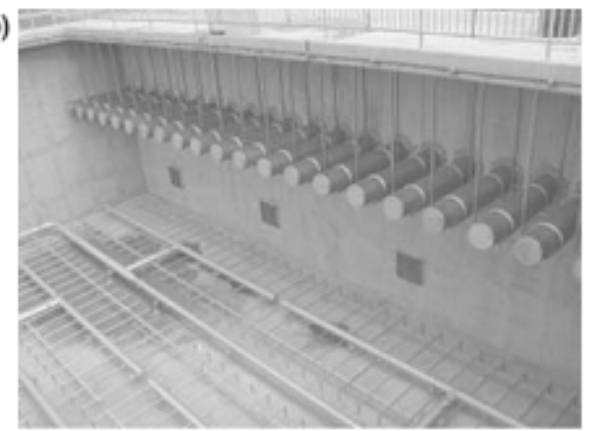

Şekil 2.1. (a) Hava dağıtım sistemi ile birlikte düşey yerleştirilmiş ızgaralar ve (b) havalandırma tertibatı boyunca yerleştirilen 1zgaralar [56].

(a)

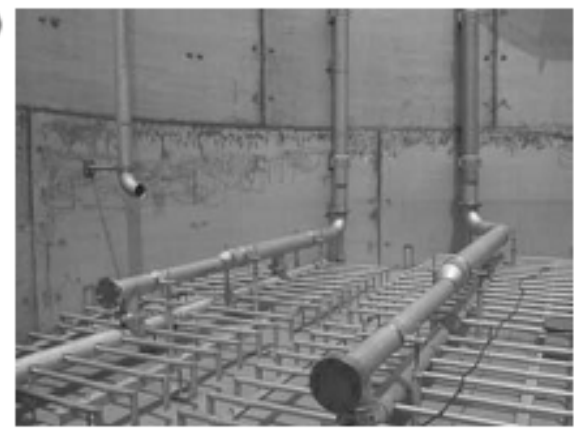

(b)

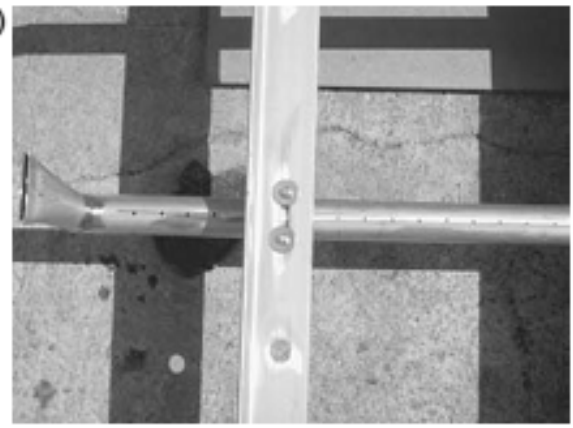

Şekil 2.2. (a) Havalandırma tertibatı ve dağııım boruları, (b) Alt kısım boyunca uzanan difüzör [56].

Hareketli yatak biyofilm reaktörlerde katı alıkonma süresi aktif çamur sistemlerine göre daha yüksektir [38] ve buna bağlı olarak biyokütlenin kaybedilme riski de daha düşüktür [39]. Sistemdeki çamur yaşının yüksek olması nitrifikasyon bakterileri gibi yavaş büyüyen mikroorganizmaların gelişimi için uygun bir ortam sağlar [4]. Dahası, hareketli yatak biyofilm reaktörlerde filamendi bakteriler ve biyolojik köpükler aktif çamur sistemlerine nazaran önemli ölçüde baskılanır [40]. Bu reaktörler kompakt ve stabil bir giderim verimine sahip olmakla beraber işletimleri basittir [41, 42]. Yüksek organik ve hidrolik yükler altında çalıştırılabilirler [43], toksik kirleticilerin etkilerine karşı güçlü bir direnç gösterirler ve yüksek bir kirletici giderim hızına sahiptirler [42]. Fenolik bir atıksu ile yapılan çalışmada hareketli yatak biyofilm reaktörlerin hem hidrolik hem de toksik şoklara büyük bir direnç gösterdiği bildirilmiştir [45]. Han ve çalışma arkadaşları kömür gazlaştırma atıksuyundan laboratuvar ölçekli hareketli yatak biyofilm reaktörlerle \%81 KOI, \%89 fenol, \%94 tiyosiyanat ve \%93 amonyum azotu giderimi sağlamışlardır [43]. Ayrıca, Dvorák çalışma arkadaşları tarafından tam ölçekli bir hareketli yatak biyofilm reaktörde $\% 75$ ile $\% 99$ arasında siyanid giderimi sağlaması bu teknolojinin toksik kirleticilere karşı direncinin diğer bir göstergesidir [40].

Hareketli yatak biyofilm reaktör sistemlerinde, temizleme ve geri yıkama gereksinimleri daha azdır [47], tıkanma problemleri görülmez ve yük kayıpları oldukça düşüktür [44]. Aşırı yük altında çalışan mevcut tesislere yeni tank inşası yapılmadan bu teknoloji kolaylıkla uygulanabilmektedir [48]. İleride debi ve/veya organik yüklerde meydana gelecek artışlara bağlı olarak tesis kapasitesinin artırılması da kolaydır [49]. Mevcut bir atıksu arıtma tesisinin hareketli yatak biyofilm reaktör teknolojisi ile modifikasyonunun incelendiği bir çalışmada bu teknoloji ile tesis kapasitesinin 480.000'den 1 milyona 
çıkarılabileceği sonucuna varılmıştır [50]. Trapani ve çalışma arkadaşları bir aktif çamur arıtma tesisinde havalandırma tankına taşıyıcı ilave ettikten sonra hidrolik yükün iki katına çıkarılmasına rağmen hareketli yatak biyofilm reaktörlerin aktif çamur prosesine nazaran daha iyi bir performans sergilediğini bildirmişlerdir [48]. Brinkley ve çalışma arkadaşları ise bir ilaç sanayisine ait mevcut bir atıksu arıtma tesisinde yaptıkları çalışmada hareketli yatak biyofilm reaktör teknolojisi ile \%98 BOI giderimi elde etmişlerdir [33]. Şimdiye kadar hareketli yatak biyofilm reaktörler evsel ve endüstriyel atıksuların arıtımında, içme suyu arıtımında ve atıksu arıtma tesislerinin iyileştirilmesinde başarı ile kullanılmıştır [51, 30]. Hareketli yatak biyofilm reaktörlerin kullanıldığı pilot ve tam ölçekli uygulamalar nitrifikasyon, organik madde ve azot gideriminde bu reaktörlerin başarı ile kullanıldığını ortaya koymuştur [35]. Kermani ve çalışma arkadaşları laboratuvar ölçekli, seri bağlı anaerobik, anoksik ve aerobik birimlerden oluşan dört reaktör ile optimum koşullarda \%99.72 amonyum, \%96.9 KOI, \%86.4 toplam azot ve \%95.8 toplam fosfor giderimi elde etmişlerdir [1]. Błażejewski ve çalışma arkadaşları ise yaptıkları bir çalışmada septik tank çıkış suyundan \%88'e kadar karbon ve \%64'e kadar azot giderimi sağlamışlardır [43]. Şekil 3'de farklı uygulamalar için sık kullanılan bazı akım diyagramları gösterilmiştir.

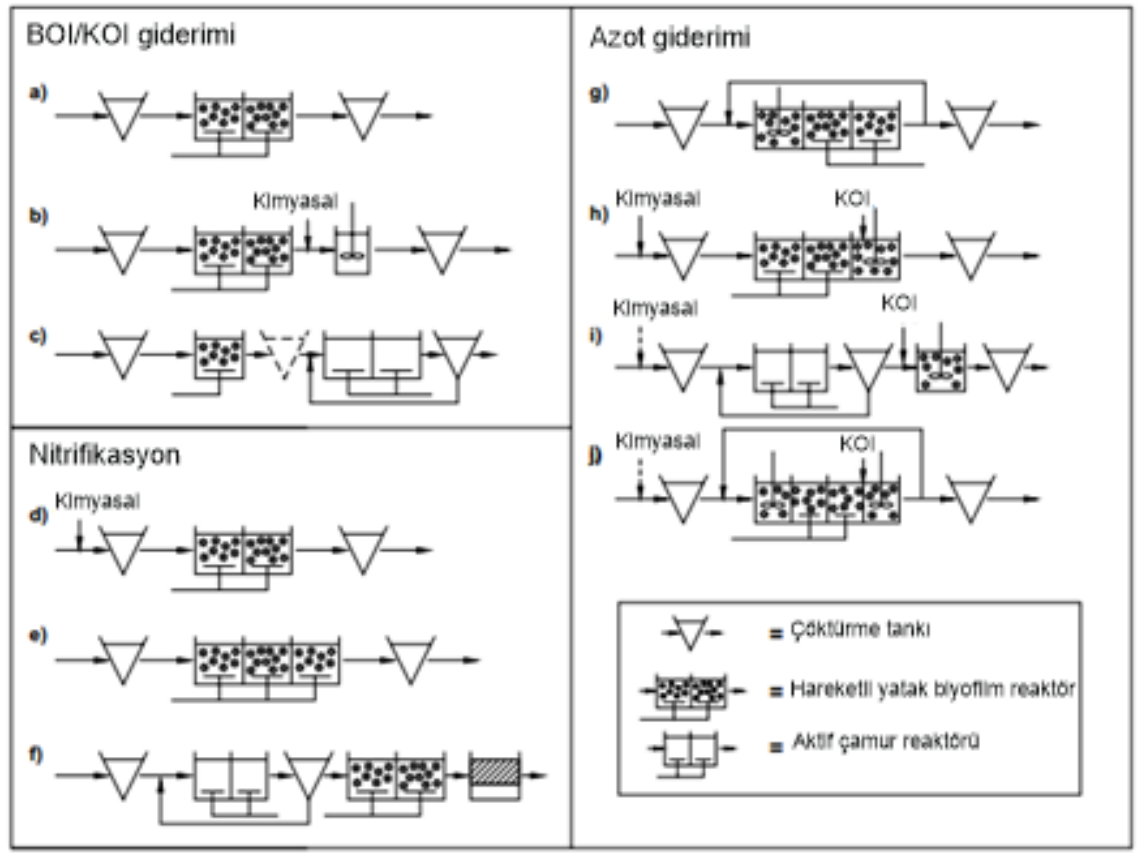

Şekil 3. Farklı uygulamalar için hareketli yatak biyofilm reaktörlerin tipik akım diyagramları [52]

\section{Hareketli Yatak Biyofilm Reaktörlerde Organik Madde ve Nutrient Giderim}

\section{Mekanizmaları}

Ødegaard atıksuyun türüne göre organik madde giderimi için hareketli yatak biyofilm reaktörlerdeki bekleme süresinin 30-90 dakika arasında değiştiğini bildirmiştir [52]. Bu değerler Öztürk ve çalışma arkadaşları tarafından konvansiyonel aktif çamur prosesleri için belirtilen değerlere göre (4-8 saat) oldukça düşüktür [53]. Tablo 1'de, Norveç’te hareketli yatak biyofilm reaktör teknolojisi ile çalışan iki arıtma tesisinden elde edilen arıtma sonuçları gösterilmiştir. 
Tablo 1. Organik madde ve fosfor giderimi için Norveç’te iki tesiste elde edilen arıtma sonuçları [52]

\begin{tabular}{|c|c|c|c|c|c|c|}
\hline \multirow[b]{2}{*}{ Parametre } & \multicolumn{3}{|c|}{ Steinshold Arıtma Tesisi } & \multicolumn{3}{|c|}{ Eidsfoss Arıtma Tesisi } \\
\hline & $\begin{array}{c}\text { Giriş } \\
\text { (mg/L) }\end{array}$ & $\begin{array}{c}\text { Çıkış } \\
\text { (mg/L) }\end{array}$ & \% giderim & $\begin{array}{c}\text { Giriş } \\
\text { (mg/L) }\end{array}$ & $\begin{array}{c}\text { Çıkış } \\
\text { (mg/L) }\end{array}$ & $\%$ giderim \\
\hline BOI - Ortalama & 398 & 10 & 97,4 & $77^{1}$ & $6,3^{1}$ & $91,8^{1}$ \\
\hline Maksimum & 1720 & 38 & 99,7 & 182 & 9,8 & 94,4 \\
\hline Minumum & 120 & 5 & 93,5 & 32 & 4,2 & 83,6 \\
\hline KOI - Ortalama & 833 & 46 & 94,4 & - & - & - \\
\hline Maksimum & 2760 & 130 & 98,4 & & & \\
\hline Minumum & 190 & 30 & 83,2 & & & \\
\hline Toplam P - Ortalama & 7,1 & 0,30 & 95,8 & 9,8 & 0,17 & 98,2 \\
\hline Maksimum & 12,0 & 0,72 & 98,8 & 27,5 & 0,94 & 99,8 \\
\hline Minumum & 4,0 & 0,12 & 92,6 & 4,4 & 0,03 & 88,3 \\
\hline Askıda katılar - Ortalama & - & 21 & - & - & 11 & - \\
\hline Maksimum & & 30 & & & 27 & \\
\hline Minumum & & 8 & & & 5 & \\
\hline
\end{tabular}

1: Bu değerler çözünmüş organik karbon esasına dayalıdır.

Hareketli yatak biyofilm reaktörlerin kullanıldığı bazı endüstriler; kağıt, peynir üretimi, mezbaha, rafineri ve gazete kağıdı endüstrisi olarak sıralanabilir [45]. Hegazy ve çalışma arkadaşları kağıt endüstrisine ait bir atıksudan hem aktif çamur hem de hareketli yatak biyofilm reaktör teknolojisini kullanarak \%98.7 KOI, \%95.9 BOI ve \%98 AKM giderimi sağlamışlardır [29]. Qui ve çalışma arkadaşları ise süt endüstrisine ait atıksudan $35{ }^{\circ} \mathrm{C}$ 'lik mezofilik koşullar altında, anaerobik hareketli yatak biyofilm reaktörle \%86.3-73.2 oranında KOI giderimi sağlamışlardır [54].

Diğer birçok biyofilm reaktörde olduğu gibi hareketli yatak biyofilm reaktörlerde nitrifikasyon süreci; organik yük, çözünmüş oksijen, amonyum konsantrasyonu, sıcaklık, alkalinite ve pH gibi birçok parametreden etkilenmektedir [56]. Toplam amonyum azotu gideri hızı, çözünmüş oksijen konsantrasyonu ve organik yük arasındaki ilişki Şekil 4'de gösterildiği gibidir. Şekil 4b'de görüldüğü gibi amonyum konsantrasyonu sadece düşük amonyum konsantrasyonlarında nitrifikasyon hızını sınırlandırabilmektedir [52]. Geleneksel proseslerin aksine hareketli yatak biyofilm reaktörler düşük sıcaklıklarda nitrifikasyonun gerçekleştirilmesine ve sürdürülmesine olanak sağlamaktadır. Salvetti ve çalışma arkadaşları sıcaklığın nitrifikasyon üzerine olan etkisini inceledikleri bir çalışmada, sınırlı amonyak koşullarında biyolojik sıcaklık sabitinin 1.086 ve 1.109 arasında değiştiğini, sınırlı oksijen koşullarında ise 1.023-1.081 arasında değiştiğini raporlamışlardır [36]. Bu değerler Rusten ve çalışma arkadaşları tarafından gözlenen değerlerle (1.09'luk bir sıcaklık sabiti) ile uyumludur. Ayrıca 7 ile $18{ }^{\circ} \mathrm{C}$ aralığında artan çözünmüş oksijen seviyelerine bağlı olarak sıcaklığın önemli bir etkisinin olmadığı gözlenmiştir [57]. Delatolla ve çalışma arkadaşları tarafindan yapılan çalışmada $1{ }^{\circ} \mathrm{C}$ sıcaklığa uzun süreli maruziyet sonucunda nitrifikasyon süreci açısından reaktör kararlığını korumuştur ve biyokütle kaybı yaşanmamıştır [58]. Ancak Wang ve çalışma arkadaşları hareketli yatak biyofilm reaktörlerde $5^{\circ} \mathrm{C}$ 'nin altında nitrifikasyonun inhibe olduğunu gözlemlemişlerdir [64]. 


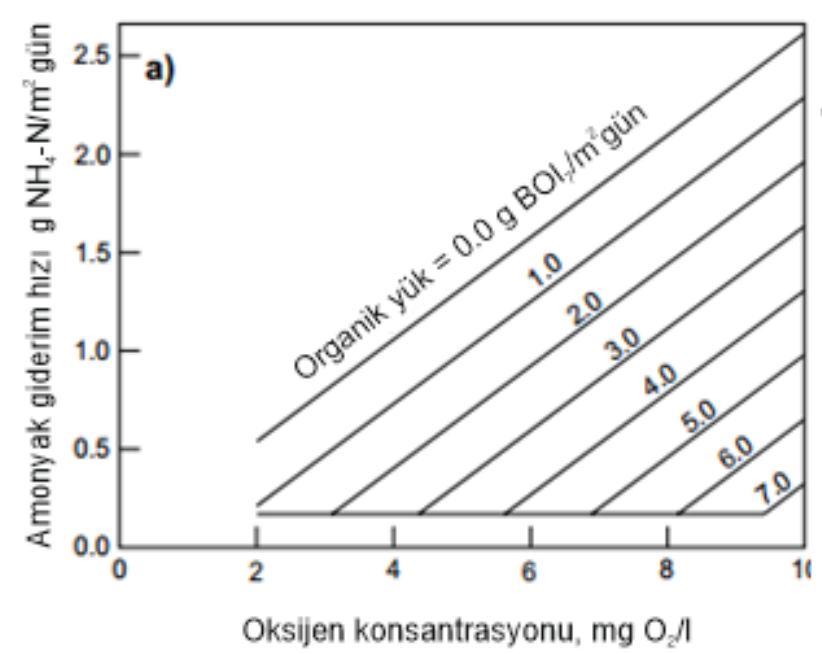

Oksijen konsantrasyonu, $\mathrm{mg} \mathrm{O}_{2} / 1$

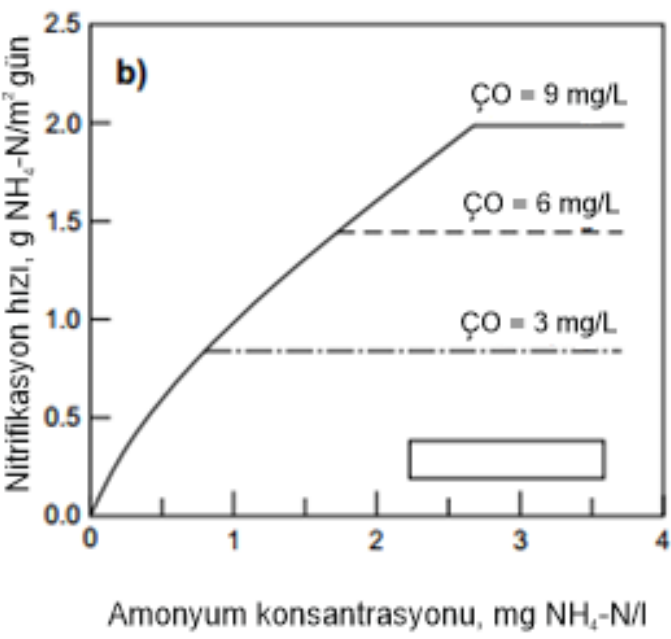

Şekil 4. Hareketli yatak biyofilm reaktörlerde $15{ }^{\circ} \mathrm{C}$ 'de organik yük ve çözünmüş oksijen konsantrasyonunun toplam amonyum azotu giderim hizına etkisi [52]

Biyofilmdeki difüzyon etkisinden dolayı nitrifikasyon hızı toplam amonyum azotu ve çözünmüş oksijen konsantrasyonuna oldukça yüksek bağlılık gösterir [12]. Wang ve çalışma arkadaşları hareketli yatak biyofilm reaktörlerde amonyum yükünün artması ile amonyum giderim veriminin arttığını gözlemlemişlerdir ve yüksek amonyak yüklerinde (6 mg/L $\left.\mathrm{NH}_{4}-\mathrm{N}\right) \% 95.6$ oranında $\mathrm{NH}_{4}-\mathrm{N}$ giderim verimi elde etmişlerdir [10]. Bu durum Ødegaard tarafindan yapılan çalışma ile uyumluluk göstermektedir (Şekil 4b). Kouba ve çalışma arkadaşları 21 ve $15{ }^{\circ} \mathrm{C}$ 'de işletilen biyofilm reaktörlerde sırasıyla 300 ve $75 \mathrm{mg} / \mathrm{L}$ 'lik amonyum azotu konsantrasyonlarında bile nitrit oksitleme bakterilerinin inhibe olmadığını bildirmişlerdir [59]. Ancak $100 \mu \mathrm{m}$ 'den daha fazla olan biyofilm kalınlıkları amonyağın biyofilme sadece kısmen nüfus etmesine izin vermektedir [36].

Taşıyıcılar üzerindeki hareketsiz mikrobiyal hücreler eş zamanlı olarak nitrifikasyon ve denitrifikasyonun gerçekleştirilmesini sağlar [63]. Wang ve çalışma arkadaşları tarafından hareketli yatak biyofilm reaktörler kullanılarak eş zamanlı nitrifikasyon - denitrifikasyon mekanizmaları ile nutrient giderimi araştırılmıştır ve yaklaşık \%89.9 toplam azot ve \%90.6 toplam fosfor giderimi sağlanmıştır [9]. Zhan ve Rodgers iki ön denitrifikasyon birimi, bir kombine karbon giderimi ve nitrifikasyon birimi, üç nitrifikasyon biriminden oluşan hareketli yatak biyofilm reaktör prosesi kullanarak $11{ }^{\circ} \mathrm{C}$ 'lik sicaklıkta PVC taşıyıcılarla sentetik bir atıksudan \%94-96 oranında karbon ve \%77-82 oranında azot giderimi sağlamakla beraber \%94-98 oranında denitrifikasyon verimi elde etmişlerdir [62]. Zinatizadeh ve Ghaytooli eş zamanlı nitrifikasyon ve denitrifikasyon mekanizmaları ile \%50 doluluk oranında ve 12 saatlik hidrolik bekleme süresinde \%88 oranında KOI giderimi sağlamışlardır [55]. Wang ve Chu biyolojik olarak bozunabilir bir polimeri karbon kaynağı olarak kullanarak eş zamanlı olarak nitrifikasyon ve denitrifikasyon mekanizmaları ile 18.5 saatlik hidrolik bekleme süresinde azotun \%74.6'sını gidermişlerdir. Yine de hareketli yatak biyofilm reaktörlerde denitrifikasyon için harici bir karbon kaynağına ihtiyaç duyulabilmektedir [46]. Luostarinen ve çalışma arkadaşları hareketli yatak biyofilm reaktörleri kullanarak anaerobik olarak ön arıtılmış bir atıksudan düşük sıcaklıklarda azot ve KOI giderimini incelemişlerdir. Çalışmalarında \%50-60 arasında azot ve \%40-70 arasında KOI giderim verimi elde etmişlerdir. Tam nitrifikasyon sağlamakla beraber denitrifikasyonun karbon yetersizliği nedeniyle sınırlandığını bildirmişlerdir [2]. Bill ve çalışma arkadaşları hareketli yatak biyofilm reaktörlerde etanol, 
metanol, gliserol ve sülfid'i elektron verici olarak kullanarak denitrifikasyon sürecini incelemiş̧lerdir. Sülfid elektron verici olarak kullanıldığında denitrifikasyon hızı maksimuma ulaşmıştır. Etanol ve gliserol elektron verici olarak kullanıldığında ise reaktörde maksimum biyofilm kütlesi elde edilmiştir [63]. Mehrdad ve çalışma arkadaşları ise bir atıksu arıtma tesisinde, hareketli yatak biyofilm reaktörlerdeki anammox aktivitesini araştırmışlardır ve başlangıçta elde ettikleri \%70'lik toplam inorganik azot gideriminin alkalinite tarafından sınırlandığını bildirmişlerdir [26].

Hareketli yatak biyofilm reaktörlerin diğer biyolojik arıtım prosesleriyle birlikte kullanımı mümkündür. Torkaman, ve çalışma arkadaşları modifiyeli Ludzack-Ettinger formundaki aerobik ve anoksik hareketli yatak biyofilm reaktörlerle çalışma yapmışlardır. 1.5 ile 3.375 saat arasında değişen hidrolik bekleme sürelerinde KOI giderim veriminin \%87.3-98.8 arasında değiştĭğini gözlemlemişlerdir. Aynı çalışmada maksimum nitrifikasyon hızını $3.05 \mathrm{~g} \mathrm{NH}_{4} / \mathrm{m}^{2}$ gün ve denitrifikasyon hızını ise $2.47 \mathrm{~g}$ $\mathrm{NO}_{3} / \mathrm{m}^{2}$ gün olarak raporlamışlardır [60].

Hareketli yatak biyofilm reaktörler son zamanlarda membran reaktörlerle kombine bir şekilde yaygın olarak kullanılmaktadır. Yang ve çalışma arkadaşları kesikli işletilen hareketli yatak membran biyoreaktör ile \%93.5 KOI, \%82.6 toplam azot, \%95.6 amonyum azotu ve \%84.1 oranında toplam fosfor giderimi sağlamışlardır [61]. Poyatos ve çalışma arkadaşları ise anoksik ve aerobik zonlardan oluşan membran reaktör ve hareketli yatak biyofilm reaktör kombinasyonu ile 36.47 saatlik hidrolik bekleme süresinde $\% 67.34 \pm 11.22$ oranında azot ve $\% 50.65 \pm 11.13$ oranında fosfor giderimi sağlamışlardır [20].

\section{Hareketli Yatak Biyofilm Reaktörlerde Kullanılan Taşıyıcı Malzemeler}

Hareketli yatak biyofilm reaktörlerde taşıyıcı elemanlar çıkış suyu kalitesi ve arıtma verimini doğrudan etkilediği için oldukça büyük bir öneme sahiptir. Taşıyıcıların reaktördeki sürekli hareketi biyofilmin ölüm ve rejenerasyon mekanizmalarına izin vererek tıkanma risklerini önler [27]. Yapışık mikrobiyal topluluktaki süksesyonel değişimler hem aerobik hem de anaerobik mikro ortamlardan oluşan sabit bir biyofilmin gelişimine yol açar [7, 66]. Taşıyıcılar üzerindeki biyofilmin gelişimi adhezyonla başlayan, gelişme, olgunlaşma, yaşlanma ve kopma ile devam eden ve sonuçta boşalan alanlarda yeni biyofilm oluşumu ile süren dinamik bir süreçtir ve kararlı durumdaki bir biyofilmde büyüme süreci kopma süreci ile bir dengeye ulaşır [6].

Biyofilmin kopması esas olarak taşıyıcılar arasındaki çarpışmanın neden olduğu abrazyon ile meydana gelir [50]. Fonksiyonel bir biyofilm topluluğunun oluşumunda ve korunmasında biyofilmin gelişimi, adhezyonu ve kopması arasındaki denge önemlidir [67]. Ren ve çalışma arkadaşları adhezyon kuvveti ve hücre dişı polimerik bileşiklerin biyofilm oluşumunda pozitif olarak ilişkili olduğunu ve önemli bir rol oynadığını bildirmiş̧ir [41]. Taşıyı doluluk oranı bu dengenin her iki tarafını etkileyebilmektedir [66]. Daha fazla taşıyıcı mikroorganizmaların tutunması ve gelişmesi için daha fazla alan temin edebilir. Ayrıca taşıyıcı dolum oranının artması taşıyıcılar arasındaki çarpışmayı artııır ve bu taşıyıcıları hareket ettirmek için havalandırma hızının artırılması ise biyofilm üzerindeki kayma gerilmesini artıracaktır. Ancak yüksek havalandırma hızı işletme masraflarını da artıracaktır [65]. So ve çalışma arkadaşlarına göre biyofilmin gelişimi hem difüzyon hem de substratların por adveksiyonu ile sinırlandırılmaktadır [64]. 


\section{Sonuçlar}

Hareketli yatak biyofilm reaktörler atıksulardan hem organik madde hem de nutrient giderimi açısından umut gösteren bir teknolojidir. Konvansiyonel arıtma sistemlerinin içerdiği avantajları bir arada sunması açısından bu teknoloji ile atık suların biyolojik olarak daha etkili ve ekonomik bir şekilde arıtılması mümkün olmaktadır. Ayrıca çevresel koşullara ve toksik şoklara gösterdiği direnç sebebi ile kolay bir işletim imkanı sunmaktadır. Ancak yine de denitrifikasyon sürecinde karbon kaynağına ihtiyaç duyulması gibi çeşitli kısıtlamalara sahiptir. Bu teknoloji üzerine yapılacak çalışmalar neticesinde atıksuların biyolojik olarak arıtımında önemli gelişmelerin sağlanması mümkün olacaktır.

\section{Kaynaklar}

[1] Kermani M., Bina, B., Movahedian, H., Amin, M.M., Nikaein, M., “Application of Moving Bed Biofilm Process for Biological Organics and Nutrients Removal from Municipal Wastewater” American Journal of Environmental Sciences, 4, 682-689, 2008.

[2] Luostarinen, S., Luste, S., Valentin, L., Rintala, J., "Nitrogen removal from on-site treated anaerobic effluents using intermittently aerated moving bed biofilm reactors at low temperatures” Water Research, 40, 1607-1615, 2006.

[3] Poyatos, J.M., Leyva-Díaz, J.C., Calderón, K., Rodríguez, F.A., González-López, J., Hontoria, E., "Comparative kinetic study between moving bed biofilm reactor-membrane bioreactor and membrane bioreactor systems and their influence on organic matter and nutrients removal” Biochemical Engineering Journal, 77, 28-40, 2013.

[4] Mannina , G., Trapani, D.D., Viviani, G., Ødegaard, H., "Modelling and dynamic simulation of hybrid moving bed biofilm reactors: Model concepts and application to a pilot plant” Biochemical Engineering Journal, 56, 23-36, 2011.

[5] Masłon, A., Tomaszek, J.A., "A study on the use of the BioBall as a biofilm carrier in a sequencing batch reactor” Biosource Technology, 196, 577-585, 2015.

[6] Qui, W., Li, M., Gu, Q., Sun, T., Wu, G., "Influence of carrier filling ratio on the performance of moving bed biofilm reactor in treating coking wastewater” Biosource Technology, 166, 72-78, 2014.

[7] Biswas, K., Taylor, M.W., Turner, S.J., "Successional development of biofilms in moving bed biofilm reactor (MBBR) systems treating municipal wastewater” Environmental Bıtechnology, 98, 1429-1440, 2014.

[8] Poyatos, J.M., Leyva-Díaz, J.C., Martín-Pascual, J., González-López, J., Hontoria, E., “Effects of scale-up on a hybrid moving bed biofilm reactor - membrane bioreactor for treating urban wastewater” Chemical Engineering Science, 104, 808-816, 2013.

[9] Wang, X.J., Xia, S.Q., Chen, L., Zhao, J.F. Renault, N.J., Chovelon, J.M., "Nutrients removal from municipal wastewater by chemical precipitation in a moving bed biofilm reactor” Process Biochemistry, 41, 824-828, 2006.

[10] Wang, Y., Zhang, S., He, W., Wu, M., Xing, M., Yang, J., Gao, N., Yin, D., "Responses of biofilm characteristics to variations in temperature and $\mathrm{NH}_{4}{ }^{+}-\mathrm{N}$ loading in a moving-bed biofilm reactor treating micro-polluted raw water” Biosource Technology, 131, 365-373, 2013.

[11] Haandel, V., Lubbe, V.D., "Handbook of Biological Wastewater Treatment” IWA Publishing, 818p, London, 2012. 
[12] Rusten, B., Eikebrokk, B., Ulgenes, Y., Lygren, E., "Design and operations of the Kaldnes moving bed biofilm reactors” Aquacultural Engineering, 34, 322-33, 2006.

[13] Rouse, J.D., Burjca, O., Strazar, M., Levstek, M., “A pilot-plant study of a moving-bed biofilm reactor system using PVA gel as a biocarrier for removals of organic carbon and nitrogen” Water Science \& Technology, 55, 135-141, 2007.

[14] Andersen, A., Broch-Due, R., Opheim, B., "Treatment of integrated newsprint mill wastewater in moving bed biofilm reactors” Water Science and Technology, 35, 173-180, 1997.

[15] Dulkadiroğlu, H., Orhon, D., "Hareketli yataklı ardışık kesikli sistemlerde sıcaklığın nitrifikasyon hızı üzerine etkisi” IT Ü Mühendislik Dergisi, 2, 3-10, 2005.

[16] Mandic-Mulec, I., Pal, L., Kraigher, B., Brajer-Humar, B., Levstek, M., “Total bacterial and ammonia-oxidizer community structure in moving bed biofilm reactors treating municipal wastewater and inorganic synthetic wastewater” Bioresource Technology, 110, 135-143, 2012.

[17] Plattes, M., Henry, E., Schosseler, P.M., Weidenhaupt, A., "Modelling and dynamic simulation of a moving bed bioreactor using respirometry for the estimation of kinetic parameters" Biochemical Engineering Journal, 32, 61-68, 2006.

[18] Jaroszynski, L.W., Cicek, N., Sparling, R., Oleszkiewicz, J.A., "Importance of the operating pH in maintaining the stability of anoxic ammonium oxidation (anammox) activity in moving bed biofilm reactors” Bioresource Technology, 102, 7051-7056, 2011.

[19] Delnavaz, M., Ayati, B., Ganjidoust, H., "Prediction of moving bed biofilm reactor (MBBR) performance for the treatment of aniline using artificial neural networks (ANN)" Journal of Hazardous Materials, 179, 769-775, 2010.

[20] Poyatos, J., Martm-Pascual, J., Reboleiro-Rivas, P., Lopez-Lopez, C., Gonzalez-Lopez, J., Hontoria, E., "Influence of hydraulic retention time on heterotrophic biomass in a wastewater moving bed membrane bioreactor treatment plant” International Journal of Environmental Science and Technology, 11, 1-10, 2013.

[21] Calderón, K., Martín-Pascual, J., Poyatos, J.M., Rodelas, B., González-Martínez, A., GonzálezLópez, J., "Comparative analysis of the bacterial diversity in a lab-scale moving bed biofilm reactor (MBBR) applied to treat urban wastewater under different operational conditions” Bioresource Technology, 121, 119-126, 2012.

[22] Poyatos, J.M., Leyva-Díaz, J.C., López-López, C., Martín-Pascual, J., Muñío, M.M., “Kinetic study of the combined processes of a membrane bioreactor and a hybrid moving bed biofilm reactor-membrane bioreactor with advanced oxidation processes as a post-treatment stage for wastewater treatment” Chemical Engineering and Processing, 91, 57-66, 2015.

[23] Dupla, M., Comeau, Y., Parent, S., Villemur, R., Jolicoeur, M., “Design optimization of a selfcleaning moving-bed bioreactor for seawater denitrification” Water Research, 40, 249-258, 2006.

[24] Pastorelli, G., Canziani, R., Pedrazzi, L., Rozzi, A., "Phosphorus and nitrogen removal in moving-bed sequencing batch biofilm reactors” Water Science \& Technology, 40, 169-176, 1999.

[25] Chen, S., Sun, D., Chung, J.S., "Treatment of pesticide wastewater by moving-bed biofilm reactor combined with Fenton-coagulation pretreatment” Journal of Hazardous Materials, 144, 577-584, 2007.

[26] Mehrdad, M., Park, H., Ramalingam, K., Fillos, J., Beckmann, K., Deur, A. and Chandran, K., "Anammox moving bed biofilm reactor pilot at the 26th Ward wastewater treatment plants in 
Brooklyn, New York: start-up, biofilm population diversity and performance optimization" Water Science \& Technology, 70, 1448-1455, 2014.

[27] Trapani, D.D., Mannina, G., Torregrossa, M. and Viviani, G., "Hybrid moving bed biofilm reactors: a pilot plant experiment” Water Science \& Technology, 57, 1539-1545, 2008.

[28] Accinelli, C., Saccà, M.L., Mencarelli, M., Vicari, A., “Application of bioplastic moving bed biofilm carriers for the removal of synthetic pollutants from wastewater" Bioresource Technology, 120, 180-186, 2012.

[29] Hegazy, B.E., Fouad, H.A., Kamel, M.M., "Moving Bed Biofilm Reactor With Activated Sludge For Treating Paper Industrial Wastewater” International Journal of Academıc Research, 5, 2013.

[30] Wang, J., Chu, L., "Comparison of polyurethane foam and biodegradable polymer as carriers in moving bed biofilm reactor for treating wastewater with a low $\mathrm{C} / \mathrm{N}$ ratio” Chemosphere, 83, 6368, 2011.

[31] Jaroszynski, L.W., Cicek, N., Sparling, R., Oleszkiewicz, J. A., "Impact of free ammonia on anammox rates (anoxic ammonium oxidation) in a moving bed biofilm reactor" Chemosphere, 88, 188-195, 2012.

[32] Cheng, W., Liu, H., Wang, M., Wang, M., "The effect of bubble plume on oxygen transfer for moving bed biofilm reactor” Journal of Hydrodynamics, 26, 664-667, 2014.

[33] Brinkley, J., Johnson, C.H., Souza, R., “Moving bed biofilm reactor technology - A full-scale installation for treatment of pharmaceutical wastewater” Chemical Business, March 2013, 5057, 2013.

[34] Zimmerman, R.A., Richard, D., Lynne, S. and Lin, W., "Is Your Moving Bed Biofiim Reactor (MBBR) Running on All Cylinders?” Proceedings of the Water Environment Federation, 29 October-2 November, 6238-6265, Washington DC, 2005.

[35] Aygün, A., "Hareketli Yatak Biyofilm Reaktörde (HYBR) Çeşitli Organik ve Hidrolik Yüklerin Atıksu Arıtma Verimine Etkisi” Selçuk Üniversitesi, Fen Bilimleri Enstitüsü, Yüksek Lisans Tezi, 155s, Konya, 2006.

[36] Salvetti, R., Azzellino, A., Canziani, R., Bonomo, L., "Effects of temperature on tertiary nitrification in moving-bed biofilm reactors” Water Research, 40, 2981-2993, 2006.

[37] Mannina, G., Trapani, D. D., Torregrossa, M., Viviani, G., "Modelling of hybrid moving bed biofilm reactors: a pilot plant experiment” Water Science \& Technology, 55, 237-246, 2007.

[38] Liu, Y., Shi, Y., Huang, C., Rocha, K.C., El-Din, M.G., “Treatment of oil sands process-affected water using moving bed biofilm reactors: With and without ozone pretreatment” Biosource Technology, 192, 219-227, 2015.

[39] Ateia, M., Nasr, M., Yoshimura, C. and Manabu, F., "Organic matter removal from saline agricultural drainage wastewater using a moving bed biofilm reactor” Water Science \& Technology, 72, 1327-1333, 2015.

[40] Dvorák, L., Lederer, T., Jirku, V., Masák, J., Novák, L., “Removal of aniline, cyanides and diphenylguanidine from industrial wastewater using a full-scale moving bed biofilm reactor” Process Biochemistry, 49, 102-109, 2014.

[41] Ren, H., Zhu, Y., Zhang, Y., Geng, J., Xu, K., Huang, H., Ding, L., "Physicochemical characteristics and microbial community evolution of biofilms during the start-up period in a moving bed biofilm reactor” Biosource Technology, 180, 345-351, 2015. 
[42] Borkar, R.P, Gulhane M.L, and Kotangale A.J., "Moving Bed Biofilm Reactor - A New Perspective in Wastewater Treatment” Journal Of Environmental Science, Toxicology And Food Technology, 6, 15-21, 2013.

[43] Han, H., Zhuang, H., Jia, S., Zhao, Q., Hou, B., “Advanced treatment of biologically pretreated coal gasification wastewater using a novel anoxic moving bed biofilm reactor (ANMBBR)biological aerated filter (BAF) system” Biosource Technology, 157, 223-230, 2014.

[44] Makowska, M., Spychała, M., Błażejewski, R., "Treatment of Septic Tank Effluent in Moving Bed Biological Reactors with Intermittent Aeration” Polish Journal of Environmental Studies, 18, 1051-1057, 2009.

[45] Borghei, S.M., Hosseini, S.H., "The treatment of phenolic wastewater using a moving bed biofilm reactor” Process Biochemistry, 39, 1177-1181, 2004

[46] Wang, J., Chu, L., "Nitrogen removal using biodegradable polymers as carbon source and biofilm carriers in a moving bed biofilm reactor” Chemical Engineering Journal, 170, 220-225, 2011.

[47] Dezotti, M., Bassin, J.P., Geraldo L., "Nitrification of industrial and domestic saline wastewaters in moving bed biofilm reactor and sequencing batch reactor" Journal of Hazardous Materials, 185, 242-248, 2011.

[48] Trapani, D.D., Mannina, G., Torregrossa, M. and Viviani, G., "Comparison between hybrid moving bed biofilm reactor and activated sludge system: a pilot plant experiment” Water Science \& Technology, 61, 891-902, 2010.

[49] Tawfik, A., "Polyurethane” Edited by Zafar, F., Sharmin, E., InTech, US, 355-380, 2012.

[50] Mannina, G. and Viviani, G., "Hybrid moving bed biofilm reactors: an effective solution for upgrading a large wastewater treatment plant” Water Science \& Technology, 60, 1103-1116, 2009.

[51] Ødegaard, H., "Innovations in wastewater treatment: the moving bed biofilm process" Water Science \& Technology, 53, 17-33, 2006.

[52] Ødegaard, H., “The moving bed biofilm reactor” Water Environmental Engineering And Reuse Of Water, 250-305, 1999.

[53] Öztürk, İ., Timur, H., Koşkan, U., “Atıksu Arıtımının Esasları” T.C Çevre ve Orman Bakanlı̆̆g, 468s., Ankara, 2005.

[54] Qui, R., Wang, S., Chandrasekhara, N.R., Moletta, R., "Performance and kinetic evaluation of anaerobic moving bed biofilm reactor for treating milk permeate from dairy industry" Bioresource Technology, 100, 5641-5647, 2005.

[55] Zinatizadeh, A.A.L., Ghaytooli, E., "Simultaneous nitrogen and carbon removal from wastewater at different operating conditions in a moving bed biofilm reactor (MBBR): Process modeling and optimization” Journal of the Taiwan Institute of Chemical Engineers, 53, 98-111, 2015.

[56] Water Environment Federation (WEF), “Biofilm Reactors” WefPress, Wef Manual of Practice No: 35, 608s, US, 2010

[57] Rusten, B., Hem, L.J., Ødegaard, H., "Nitrification of municipal wastewater in moving-bed biofilm reactors” Water Environment Research, 67, 75-86, 1995. 
[58] Delatolla, R., Hoang, V., Abujamel, T., Mottawea, W., Gadbois, A., Laflamme, E., Stintzi, A., "Nitrifying moving bed biofilm reactor (MBBR) biofilm and biomass response to long term exposure to $1{ }^{\circ}$ C” Water Research, 49, 215-224, 2014.

[59] Kouba, V., Catrysse, M., Stryjova, H., Jonatova, I., Volcke, E., Svehla, P. and Bartacek, J., “The impact of influent total ammonium nitrogen concentration on nitrite-oxidizing bacteria inhibition in moving bed biofilm reactor” Water Science \& Technology, 69, 1227-1233, 2014.

[60] Torkaman, M., Borghei, S.M., Tahmasebian, S. and Andalibi, M.R., “ Nitrogen removal from high organic loading wastewater in modified Ludzack-Ettinger configuration mbbr system” Water Science \& Technology, 72, 1274-1282, 2015.

[61] Yang, F., Yang, S., Fu, Z., Wang, T., Lei, R., "Simultaneous nitrogen and phosphorus removal by a novel sequencing batch moving bed membrane bioreactor for wastewater treatment" Journal of Hazardous Materials, 175, 551-557, 2010.

[62] Zhan, X., Rodgers, M., "Biological nitrogen removal using a vertically moving biofilm system” Bioresource Technology, 93, 313-319, 2004.

[63] Poyatos, J.M., Leyva-Díaz, J.C., González-Martínez, A., González-López , J., Muñío, M.M., "Kinetic modeling and microbiological study of two-step nitrification in a membrane bioreactor and hybrid moving bed biofilm reactor-membrane bioreactor for wastewater treatment” Chemical Engineering Journal, 259, 692-702, 2015

[64] So, M., Naka, D., Goel, R., Terashima, M. and Yasui, H., "Modelling clogging and biofilm detachment in sponge carrier media” Water Science \& Technology, 69, 1298-1303, 2014..

[65] Anderson, M.J., Parks, P.J., Peterson, M.L., “A mucosal model to study microbial biofilm development and anti-biofilm therapeutics” Journal of Microbiological Methods, 92, 201-208, 2013.

[66] Wang, R.C., Wen, X.H., Qian, Y., "Influence of carrier filling ratio on the performance and microbial characterisitics of a suspended carrier biofilm reactor” Process Biochemistry, 40, 2992-3001, 2005.

[67] Ren, H., Huang, H., Ding, L., Geng, J., Xu, K., Zhang, Y., “Aging biofilm from a full-scale moving bed biofilm reactor: Characterization and enzymatic treatment study” Bioresource Technology, 154, 122-130, 2014. 